\title{
Correlation of Bottle Feeding to Malocclusion on Indonesian 3- 6-year-old Preschool Children in Pariaman City, West Sumatera, Indonesia
}

\author{
Hidayati $^{1}$, Idral Purnakarya ${ }^{2}$, Fikri Al Hafiz ${ }^{3}$, Desy Purnama Sari ${ }^{4}$ \\ hidayati@dent.unand.ac.id \\ Department of Preventive Dentistry Faculty of Dentistry Universitas Andalas \\ Department of Public Health Faculty of Dentistry Universitas Andalas
}

\begin{abstract}
Bottle feeding is one of aetiology in dental and skeletal malocclusion. This study aimed to evaluate the correlation of bottle feeding to malocclusion on 3-6-year-old preschool children in PAUD and TK Bato Pariaman City, West Sumatera, Indonesia. A cross-sectional survey of 41 preschool children, aged 3-6 years were chosen randomly. Historical bottle feeding habit collected by interviewing their parents based on a selfreported questionnaire. Clinical examination of malocclusion was recorded by measuring the overjet, overbite and dental or skeletal anomaly. Then, the data were analyzed by computerized analysis using the chi-square test. Almost of respondent has malocclusion (58.54\%) including abnormal overjet $41.46 \%$, posterior crossbite $(4.88 \%)$, open bite (4.88\%), abnormal overjet with posterior crossbite (8.33\%) and abnormal overjet with open bite $(2.44 \%)$ and only $41.46 \%$ respondent has normal occlusion $(41.46 \%)$. Chi square-test showed that significant correlation of bottle feeding to malocclusion $(\mathrm{p}=0,001)$. So, it is concluded that bottle feeding as an aetiology of malocclusion in preschool children, so an adequate habit repaired play an important role as a preventive program to decrease the children's malocclusion.
\end{abstract}

Keyword: bottle feeding, preschool children, malocclusion.

\section{Introduction}

The World Health Organization incorporates malocclusion into the handicapping part of dentofacial anomalies, and it can cause dis-configuration and impact on physical and emotional conditions (Sandeep, 2012). According to Narbutyte et al. (2013), malocclusion is a state deviating from normal occlusion thus irregularity of teeth beyond the acceptable normal threshold. Malocclusion becomes the third most common dental and oral health problem in the world (Haralur, 2014). This condition caused by multifactor such as genetics, the environment including soft food, and lack of stimulation for adequate jaw growth, bad habits, missing teeth (Sandeep, 2012). Malocclusion 
has an impact on social life and aesthetic outlook because children tend to hide their smile (Badran, 2010). In addition, malocclusion also affects the pronunciation, functional, and symmetrical faces (Talapaneni et al., 2012).

The prior research showed that the prevalence of malocclusion in each country various from $11-93 \%$, this is due to multiple reasons such as criteria of subject selection and the research location was conducted (Haralur, 2014). Study in Benin City, Nigeria on 229 men and 212 women with an average age of 13.52 years showed that $15.9 \%$ of the study subjects had normal occlusion; $80.7 \%$ class I Angle; $1.1 \%$ class II division 1 and $0.5 \%$ class II division 2; as well as $1.8 \%$ Angle class III malocclusion (Sandeep, 2012).

Sigmun Freud, a psychologist argued that children aged 0-18 months be in oral phase. Its means as psychosocial (biological) responses, they lean put anything in their mouth (Videbeck, 2008). At the 13-16 fetal aged,a reflex to swallow and sucking has emerged in a uterus. Thus, the newborn exclusively initiate breastfed to their mom up to 12 months of age. The sucking reflex will disappear when enter the transitioning learning phase to eat. But if it still remains on an aged 3-6 year, it is considered an oral bad habit and may lead abnormalities of dental growth (Branam 2005).

In oral health, breastfeeding affected the growth and development of the stomatognathic system. The mechanism breastfeeding likewise orthodontic device even act as a protective factor against malocclusion. On the other hand, excessive bottle feeding can lead to developing dental or skeletal malocclusion. It may be caused by size, type, texture and elasticity of artificial nipple differ from mother's breast, then caused inharmoniously the positions of the arches, cheeks and tongue. Thus, it leads to restriction of normal vertical and transverse palatal growth by non-psychological pressure and causes some malocclusion in which abnormal overjet, open bite, crossbite and improper alignment of teeth (Chen et al., 2015; Narbutyte, 2013; Radzi et al., 2005; Thomaz et al., 2018).

According to Radzi et al.'s study (2005), there is a positive correlation between bottle feeding and dental overjet. It is similar to Charcut's research on children aged 2-6 years have overjet more than $3 \mathrm{~mm}$ with bottle feeding habit. We also took pre-survey on 15 preschool children in Pariaman City, West Sumatera Indonesia. The data showed that five from fifteen children with bottle feeding have malocclusion with overjet $>3 \mathrm{~mm}$. So, the purpose of this study was to evaluate the correlation of bottle feeding to malocclusion on 3-6-yearold preschool children in PAUD and TK Bato Pariaman City, Indonesia. 


\section{Methods}

PAUD and TK provide early childhood education with supported by the nearest cadre or village volunteer and financed by the Indonesian government. The concept of PAUD is managed and organised from, by and for the community in obtaining a primary education. A cross-sectional survey was conducted in two preschools at Pendidikan Anak Usia Dini (PAUD) and Taman Kanak-Kanak (TK) Bato, Pariaman City, West Sumatera, Indonesia. Total population was 60 preschool children (15 from PAUD and 45 from TK), but only forty-one children aged 3-6 years old with were eligible in this study selected by random sampling technique with the following criteria: 1) all deciduous teeth are eruption; 2) active student in PAUD and TK Bato; 3) normal and healthy children; 4) bottle feeding history. Children with a bad habit, dysfunction and maxillofacial disorder were excluded in this study.

The study was approved by The Committee of the Research Ethics, Faculty of Medicine, Andalas University (165/KEP/FK/2018) and held by two months from January-March 2018. The data were collected with criteria 1) reviewing the total preschool children aged 3-6 years children at PAUD and TK Bato, 2) examine the children teeth to determine the occlusion, 3) prepare the selfadministered questionnaire, 4) interviewing the parent. The collected data was recorded basic characteristic demographics of the respondent, classified the malocclusion and bottle feeding characteristic. Clinical examination was to asses the dental or skeletal anomaly and measure the overjet and overbite. Chisquare test was used to evaluate the correlation of bottle feeding to malocclusion on 3-6-year-old preschool children in PAUD and TK Bato Pariaman City, West Sumatera, Indonesia.

\section{Result}

According to Table 1, abnormal overjet has the highest percentage than other types of malocclusion (70.83\%). Posterior crossbite, open bite, abnormal overjet with posterior crossbite has the same rate $(8.33 \%)$. Whereas, abnormal overjet with open bite was the lowest percentage of malocclusion in this study (4. $16 \%)$.

Table 1. Percentage of Malocclusion on Preschool Children in Pariaman City $(n=41)$

\begin{tabular}{ccc}
\hline Occlusion & Frequency (f) & Percentage (\%) \\
\hline Normal & 17 & 41.46 \\
\hline Overjet $>$ 3mm & 17 & 41.46 \\
Posterior Crossbite & 2 & 4.88 \\
Open Bite & 2 & 4.88
\end{tabular}




\begin{tabular}{ccc} 
Overjet $>3 \mathrm{~mm}+$ Posterior Crossbite & 2 & 4.88 \\
Overjet $>3 \mathrm{~mm}+$ Open Bite & 1 & 2.44 \\
\hline Total & 41 & 100 \\
\hline
\end{tabular}

Table 2. Correlation of Malocclusion to Bottle Feeding on Preschool Children in Pariaman City $(n=41)$

\begin{tabular}{|c|c|c|c|c|c|c|}
\hline \multirow{3}{*}{ Bottle feeding } & \multicolumn{4}{|c|}{ Malocclusion } & \multirow{3}{*}{ Total } & \multirow{3}{*}{$P$ value } \\
\hline & \multicolumn{2}{|c|}{ No } & \multicolumn{2}{|c|}{ Yes } & & \\
\hline & Total & $\%$ & Total & $\%$ & & \\
\hline$\leq 24$ months (2 years) & 13 & $92.9 \%$ & 1 & $7.1 \%$ & 14 & \\
\hline $25-36$ months (2-3 years) & 2 & $22.2 \%$ & 7 & $77.8 \%$ & 9 & 0.001 \\
\hline$>36$ months (> 3 years) & 2 & $11.1 \%$ & 16 & $88.9 \%$ & 18 & \\
\hline Total & 17 & $41.5 \%$ & 24 & $58.5 \%$ & 41 & \\
\hline
\end{tabular}

Table 2 showed that there is a significant correlation $(\mathrm{p}<0.05)$ and equal relationship between bottle feeding and malocclusion. The longer duration of bottle feeding possibly more potential to be malocclusion on 3-6-years-old preschool children in Pariaman City.

\section{Discussion}

This study revealed that almost children have malocclusion (48.5\%) than normal children $(41.5 \%)$. The most type of malocclusion found on children with abnormal overjet $>3 \mathrm{~mm}$ amount $70.83 \%$. When the children sucking from the bottle, the children usually put the tongue to the palatal servical on upper anterior teeth. It may be affecting anterior side and overjet distance (Branam, 2005).

The other type of malocclusion is open-bite on the anterior side $(8.33 \%)$. Abnormal motoric activities compared to breastfeeding caused by abnormal swallowing and preference to be open bite (Anisyah et al., 2006). Crossbiteposterior also found in this study, due to the activity of squeezing action and consistency of rubber bottle. It may be caused by the pressure of tongue more suppress the palatum, then intruded on palatum growth (Vigiano et al., 2004).

The long duration of bottle feeding potentially cause malocclusion, and it has vanished when the children enter the transitioning phase to eat. But it calls abnormal when it remains on the children over than 3-6-years-old. It is appropriated to Charchut (2003) revealed that children with bottle feeding have overjet more than $3 \mathrm{~mm}$. On the other hand, Millet et al. (2005) claimed that 
normal overjet on the children is $2-3 \mathrm{~mm}$. Ganesh et al' s study (2005) on 153 children aged 3-5 years in South Kanara revealed that bottle feeding in longterm could cause open bite. It is also supported by Vigiano et al.'s study on 1130 Italian children aged 3-5 years showed that posterior crossbite more founded in children with bottle feeding habit.

We revealed that a significant correlation between bottle feeding and malocclusion $(\mathrm{p}<0.05)$. Breastfeeding children more potentially have malocclusion than bottle feeding children. It may be caused by the texture, shape, type and consistency of artificial nipple. Thus, muscular force when sucking for artificial nipple affected maxillofacial growth pattern. Adequate Movement of lip, tongue, and buccinator muscle by using bottle caused imbalance of orofacial structures and leading to disturbance of maxillary development (Thomaz et al., 2018).

Meanwhile, breastfeeding versus bottle feeding as the aetiology of malocclusion still a controversial related to the duration of sucking or swallowing. But, our result found that bottle feeding as a significant predisposing factor of malocclusion with several theoretical mechanisms including: (1) Bottle children feeding use less muscle activity to extract milk from a bottle than breastfeeding, inadequate mandibular growth caused by the motion of muscle activity that can decreasing the development of muscle when sucking which may act as a functional matrix; (2) During bottle feeding, the tongue just serve to control the milk, so it also increases the prevalence of abnormal swallowing patterns or tongue thrusting habits; (3) More than 60\% children with bottle feeding predominantly presented mouth breathing or mixed breathing, which may compromise occlusion (Chen, 2015).

\section{Conclusion}

There is a significant correlation of bottle feeding to malocclusion on 3-6year-old preschool children in PAUD and TK Bato Pariaman City, Indonesia Bottle feeding was an aetiology of malocclusion in preschool children, so an adequate habit repaired plays an essential role as a preventive program to decrease the children's malocclusion.

\section{References}

Anisya I., Hayati, R. Suharsini, M. 2006. Hubungan Antara Lama Pemberian Susu Botol dan Oklusi Gigi Sulung. IJD. Hal : 388-392.

Badran, SA. 2010. The effect of malocclusion and self-perceived aesthetics on the self-esteem of a sample of Jordanian adolescents. Eur J Orthod, 32(6):638-644.

Branam S.R. 2005. Role of Oral Habits in Children. Oral Habit12: 1-2. 
Charchut, S. W., Allerd, E. N., Needleman, H. L. 2003. The Effects of Infant Feeding Patterns on the Occlusions of the Primary Dentition. J.Dent.Child. 70:197-203.

Chen X, Xia B, Ge L. 2015. Effect of breast-feeding duration, bottle-feeding duration and non-nutritive sucking habits on the occlusal characteristics of primary dentition. BMC Pediatric 15: 46.

Ganesh, M., Tandons, S., Sajida, B. 2005. Prolonged Feeding Practice and its Effects on Developing Dentition, J.Indian.Soc.Pedod.Prev.Dent, 23(3):141-45.

Haralur SB, Addas MK, Otham HI. 2014. Prevalence of malocclusion, its association with occlusal interferences and temporomandibular disorders among the Saudi sub-population. OHDM:13(2): 164-9.

Narbutyte I, Narbutyte A, Linkeviciene. 2013. The relationship between breastfeeding, bottle-feeding and development of malocclusionStomatologija, Baltic Dental and Maxillofacial Journal, 15:67-72.

Pinkham JR. 1994. Pediatric Dentistry Infancy Through Adolescence. Philadelphia: WB Saunders Co.2: 166-9, 301-7.

Radzi, Z., Yahya, NA. 2005. Relationship Between Breastfeeding and Bottle-feeding to craniofacial and Dental Development. Annal.Dent.Univ.Malay. 12:9-17.

Sanchez Molins, M., Grau, J., Lischeid, C., Ustrell, J. M. 2010. Comparative study of the craniofacial growth depending on the type of lactation received. Eur J Paediatr Dent 11, 87-92.

Sandeep G, Sonia G. Pattern of dental malocclusion in orthodontic patients in Rwanda: a retrospective hospital-based study. Rwanda Med J 2012:69(4):13-8.

Talapaneni, AK., Nuvvula, S. 2012. The association between posterior unilateral crossbite and craniomandibular asymmetry: a systematic review. J Orthod, 39(4):279-91.

Thomaz EBAF, Alves CMC, Silva LFG, Almeida CCCR, Alves MTSS, Hilgert JB, Wendland EMR. Breastfeeding versus bottle-feeding on malocclusion in children: A Meta-Analysis Study. Journal of Human Lactation: $1-21$.

Videbeck, S. L.2008. Buku Ajar Keperawatan Jiwa, EGC, Jakarta, pp. 58.

Viggiano, D Fasano, G Monaco, L Strohmenger. 2004. Breast Feeding, Bottle Feeding, and Non-Nutritive Sucking; Effects On Occlusion In Deciduous Dentition, Arch.Dis.Child., 89: 1121-1123. 